\title{
FACTORS DETERMINING OUTCOMES IN ACUTE EXACERBATIONS OF CHRONIC OBSTRUCTIVE PULMONARY DISEASE
}

\section{G. Peter Praveen Herald, Suresh Kumar Cherlopalli *.}

MD Pulmonary Medicine, Assistant Professor in Viswabharathi Medical College, Penchikalapadu, Kurnool, Andhra Prasesh, India.

\section{ABSTRACT}

Background: factors determining outcomes in acute exacerbations of chronic obstructive pulmonary disease (AECOPD) would help us to understand the incidence of acute exacerbation of COPD in the Rayalasema community of patients and the type of bacterial infections in acute exacerbations of chronic obstructive pulmonary disease in the cases admitted to Viswabharathi Medical College Hospital, Kurnool.

Subjects and Methods: 100 patients ( 72 males, 28 females) aged between 45 and 85 years were included in the study. A detail history was elicited and complete examination was done. The sputum specimen was collected using sterile sputum cups and subjected to Gram's stain, culture and biochemical reactions.

Results: Our study shows 47 positive sputum cultures out of total 100 cases. Out of 100 cases $72 \%$ were males and $28 \%$ were females. The predominant clinical feature observed in our study was cough with expectoration, exertional dyspnoea and production of mucopurulent sputum. The prevalence of Gram negative bacteria was $55 \%$ and a Gram positive bacterium was $45 \%$. Klebsiella pneumoniae was the commonest bacteria isolated (38\%) followed by Staphylococcus aureus (18\%)

Conclusions: In a developing country like India AECOPD is more common in adults more than 55 years of age due to smoking habits and high indoor pollution. This leads to a major impact on the quality of life of patients with the condition. They are a major cause of hospital admission and health care utilization.

KEY WORDS: Acute Exacerbation of COPD, Sputum Cultures, Klebsiella pneumoniae, and Staphylococcus aureus.

Address for correspondence: Dr. Suresh Kumar Cherlopalli, MD Pulmonary Medicine, Assistant Professor in Viswabharathi Medical College, Penchikalapadu, Kurnool, Andhra Prasesh, India.

E-Mail: septasure@gmail.com

\begin{tabular}{|l|l|}
\hline \multicolumn{3}{|c|}{ Online Access and Article Informtaion } \\
\hline Quick Response code & \multicolumn{1}{|c|}{ International Journal of Integrative Medical Sciences } \\
& \multicolumn{1}{|c|}{ ISSN (P): 2394 - 6318. ISSN (E): 2394 - 4137 } \\
www.imedsciences.com
\end{tabular}

\section{BACKGROUND}

Chronic obstructive pulmonary disease (COPD) is a chronic respiratory disease characterized by a decline in lung functions over time and accompanied by respiratory symptoms, primarily dyspnoea, cough, and sputum production. COPD is associated with a significant economic burden, including hospitalization, work absence and disability [1]. It is an important cause of morbidity and mortality. Its prevalence and morbidity data often underestimate the burden of disease because this disease is not diagnosed until it is clinically apparent and moderately advanced [2]. Tobacco smoking is the most important risk factor for COPD in India [3].

According to World Health Organization estimates, 65 million people have moderate to severe COPD. More than 3 million people died of COPD in 2005 corresponding to $5 \%$ of all deaths globally and it is estimated to be the third leading cause of death by 2030 . Crude estimates suggest there are 30 million COPD patients in India [4]. The COPD prevalence varies from 3\% to $8 \%$ amongst Indian males and approximately 


\section{$2.5 \%$ to $4.5 \%$ among Indian females (5).}

Acute exacerbation of COPD (AECOPD) is defined as a sustained worsening of the patient's condition, from the stable state and beyond normal day-to-day variations, that is acute in onset and necessitates a change in regular medication in a patient with underlying COPD [6]. Acute exacerbation of COPD showed a hospital mortality rate of $24 \%$ if the patient required ICU admission. This mortality rate increased to $30 \%$ if the patient was above 65 years [7]. It is both a rural and urban health problem, the prevalence varying from $1 \%$ in urban nonsmoker to $21 \%$ in rural smokers. This increasing prevalence and mortality has led to an extensive research related to these diseases. Much has been learnt about pulmonary response to irritants, particulate antigenic materials and infectious agents [8]. Current study about factors determining outcomes in acute exacerbations of chronic obstructive pulmonary disease would help us to understand the incidence of acute exacerbation of COPD in the Rayalasema community of patients and the type of bacterial infections in acute exacerbations of chronic obstructive pulmonary disease in the cases admitted to Viswabharathi Medical College Hospital, Kurnool.

\section{SUBJECTS AND METHODS}

A descriptive study over a period of 1 year from December 2016 to November 2017, Patients admitted in Viswabharathi Medical College Hospital, Kurnool with acute exacerbations of COPD. A minimum of 100 patients clinically diagnosed case of acute exacerbation of chronic obstructive pulmonary disease were included in the study. Variables included for the study were age, sex, smoking, signs and symptoms of the patient. The information regarding these variables was collected by using a pretested questionnaire.

\section{Inclusion Criteria:}

1) All patients above 40 yrs of age with or without smoking history, presenting with cough, sputum production \& exertional dyspnoea.

2) Spirometry showing features of airflow obstruction with reduction in $\mathrm{FEV}_{1}$ \& $\mathrm{FEV}_{1} / \mathrm{FVC}$ as per GOLD (9) (Global Initiative for Lung
Disease) Criteria for COPD Severity.

\section{Exclusion Criteria:}

1) Patients who are already on antibiotic treatment.

2) Patients who had evidence of bronchiectasis on a chest radiograph-PA view.

3) Patients with pulmonary tuberculosis on antitubercular medications.

4) Patients with restrictive lung disease.

5) Patients with lung malignancy.

Sputum culture: After collection and assessing the sputum, sample was sub cultured on following culture plates.

1) Blood agar - $5 \%$ sheep blood agar for isolation of hemolytic organisms.

2) Chocolate agar - For Haemophilus and Neisseria species.

3) MacConkey's agar - for isolation and differentiation of Gram negative bacilli.

These inoculated plates were then incubated for a period of 24 hours after which they were examined for evidence of bacterial growth. In case of bacterial growth on the medium, the bacteria were further identified using standard tests. In case of no growth occurring on plates, a report of no organisms grown on culture after 24 hours of incubation was dispatched to the respective units and Grams staining, Hanging drop, Catalase test, Oxidase test, Indole, Methyl red test, Voges proskauer test, Citrate utilisation test, Urease production, Hydrogen sulfide production, Sugar fermentation test, Nitrate reduction test, Coagulase production (for Staphylococci), Bile solubility test (for Streptococcus pneumoniae), and Blood agar - Bacitracin (for â-haemolytic Streptococci) tests were performed according to standard methods.

\section{RESULTS}

Table 1: Showing age distribution among 100 COPD patients.

\begin{tabular}{|c|c|c|}
\hline Age & Number & Percentage \\
\hline 45 & 12 & $12 \%$ \\
\hline 55 & 43 & $43 \%$ \\
\hline 65 & 33 & $33 \%$ \\
\hline 75 & 12 & $12 \%$ \\
\hline
\end{tabular}


Table 2: Showing sex distribution among the 100 sputum samples.

\begin{tabular}{|c|c|c|}
\hline Sex & Number & Percentage \\
\hline Male & 72 & $72 \%$ \\
\hline Female & 28 & $28 \%$ \\
\hline
\end{tabular}

Table 3: Showing the smoking pattern among 72 COPD males' patients.

\begin{tabular}{|c|c|c|}
\hline Smoking Index & Number & Percentage \\
\hline Smoking & 45 & $63 \%$ \\
\hline Non-Smoking & 27 & $38 \%$ \\
\hline
\end{tabular}

Table 4: Showing the growth pattern in 100 sputum samples.

\begin{tabular}{|c|c|c|}
\hline Growth & Number & Percentage \\
\hline Single Isolates & 39 & $39 \%$ \\
\hline Multiple Isolates & 8 & $8 \%$ \\
\hline Non-pathogenic & 53 & $53 \%$ \\
\hline
\end{tabular}

Table 5: Showing organism single isolates from sputum culture in 39 sputum samples.

\begin{tabular}{|c|c|c|}
\hline Name of the Organism & Number & Percentage \\
\hline K.pneumoniae & 15 & $38.50 \%$ \\
\hline S.aureus & 7 & $18.00 \%$ \\
\hline S. pnemoniae & 6 & $15.40 \%$ \\
\hline P. aeruginosa & 4 & $10.30 \%$ \\
\hline S. yogenes & 3 & $7.70 \%$ \\
\hline E. coli & 2 & $5.10 \%$ \\
\hline MRSA & 2 & $5.10 \%$ \\
\hline Total & 39 & \\
\hline
\end{tabular}

\section{DISCUSSION}

AECOPD is a major cause of hospital admission and health care utilization, and have a major impact on the quality of life of patients with the condition. In our study it was observed that AECOPD was prevalent in 45-85 year age group. However among them, 55-65 year age constituted $43 \%$. Thus AECOPD was common above 55 years, it is corresponds to other similar studies, because it was more commonly seen in patients with advanced lung disease as an expression of deterioration in host defenses at the bronchial mucosal level [10]. Out of one hundred (100) patients, clinically diagnosed as Acute exacerbation of chronic obstructive pulmonary disease, seventy two (72) (72\%) were males and twenty-eight (28) (28\%) were females. The ratio between male and female is 2.57:1. In our study AECOPD was more common among smokers $63 \%$ than non-smokers $38 \%$ which was similar to other studies $[8,9]$.
Among thirty nine (39) single pathogenic microbial growth twenty seven (27) (55\%) were Gram-negative bacteria and twenty two (22) (45\%) were Gram-positive bacteria. Out of thirty nine (39) single pathogenic bacteria, Klebsiella pneumoniae was the commonest bacteria isolated, in fifteen (15) cases, followed by Staphylococcus aureus isolated in seven (7) cases. Streptococcus pneumoniae was isolated in six (6) cases. Other common organisms isolate were Pseudomonas aeruginosa in four (4) cases, Streptococcus pyogenes in three (3) cases. The Gram negative organisms were more common in the patients with the most severe lung dysfunction, whereas the Gram positive bacteria predominated in the exacerbations of the patients with the mildest degree of lung function abnormalities [11]. Which matched with study conducted by Rakesh et al. [12] who found among the thirty seven single pathogenic microbial growth 19 (51.35\%) were Gram negative bacteria and 18 (48.64\%) were Gram positive bacteria.

Among the Gram negative isolates, K. pneumonia was the predominant organism isolated $38.46 \%$, Staphylococcus aureus $17.95 \%$, S. pneumoniae $15.38 \%$, P. aruginosa $10.26 \%$, S. pyogenes $7.69 \%$, E coli $5.13 \%$, MRSA $5.13 \%$. $\mathrm{H}$ influenzae was not isolated whereas study conducted in 2014 Alexandra et al. [13] H influenza predominates with $23.9 \%$ followed by Pseudomonas aeruginosa with $14.1 \%$ and Patel et al. [14] in 2014 showed Streptococcus pneumonia to be the major cause with $32 \%$ followed by S. pyogenes (16\%) and Pseudomonas (12\%). in 2015 similar study conducted by Narayanagowda DS et al. [15] also found similar findings to resent study.

\section{CONCLUSION}

Sputum culture and antibiogram helps a good and simple tool to study the aetiology \& complications, and helps in the correct treatment protocol during management of AECOPD. It also helps in screening resistant pathogens and better drug for treatment, thereby helping to decrease the mortality and morbidity. To conclude, in addition to the host genetic factors, smoking behaviour, accessibility to health care and presence of co-morbid 
conditions contribute to morbidity and mortality due to AECOPD.

\section{REFERENCES}

[1]. Rycroft CE, Heyes A, Lanza L, Becker K. Epidemiology of chronic obstructive pulmonary disease: a literature review. International J COPD. 2012; 7:457-94.

[2]. Arne M, Lisspers K, Stallberg B, Boman G, Hedenstrom $H$, Janson $C$, et.al. How often is diagnosis of COPD confirmed with spirometry?.Respiratory Medicine. 2010;104: 550-56.

[3]. Salvi S, Agrawal A. India Needs a National COPD Prevention and Control Programme.Supplement to JAPI. 2012;60:5-7.

[4]. Koul PA. Chronic obstructive pulmonary disease: Indian guidelines and the road ahead. Lung India. 2013;30(3):175-77.

[5]. Bhome AB.COPD in India: Iceberg or volcano?. J Thorac Dis. 2012;4(3):298-309.

[6]. Thomas L. Petty. The history of COPD. Int J COPD. 2006;1(1):3-14.

[7]. Kamat Sudhakar R. Chronic obstructive pulmonary disease. Lung Biol Health Dis Indian Pusputre. 1991;51:399-422.

[8]. Anto JM, Vermeire P, Vestbo J, Sunyer J. Epidemiology of chronic obstructive pulmonary disease. Eur Respir J. 2001;17(5):982-94.

[9]. Jindal SK, Aggarwal AN, Gupta D. A review of population studies from India to estimate national burden of chronic obstructive pulmonary disease and its association with smoking. Indian J Chest Dis Allied Sci. 2001;43:139-47.

[10]. Antonisen NR, Mnafreda J, Warren CP, Hershfield ES, Harding GK, Nelson NA. Antibiotic therapy in exacerbations of chronic obstructive pulmonary disease. Ann Intern Med. 1987;106:196-204.
[11]. Patricia Tille. Bacterial agents in COPD. In: Patricia Tille, eds. Bailey \& Scott's Diagnostic Microbiology. 13th ed. US: Mosby; 2013: 119.

[12]. Gerard Rakesh, T. Kasturi S. Yuvarajan. Bacterial agents causing acute exacerbations in Chronic Obstructive Pulmonary Disease (COPD) patients, their antibiograms to Extended Spectrum BetaLactamases (ESBL) production in a tertiary care hospital, India. Int J Curr Microbiol App Sci. 2013;2(11):273-82.

[13]. Alexandra Nakou, Joseph Papaparaskevas, Filia Diamantea, Nikoletta Skarmoutsou, Vlasis Polychronopoulos, Athanassios Tsakris. A prospective study on bacterial and atypical etiology of acute exacerbation in chronic obstructive pulmonary disease. Future Microbiol. 2014;9(11):1251-60.

[14]. Patel AK, Luhadia AS, Luhadia SK. sputum bacteriology and antibiotic sensitivity pattern of patients having acute exacerbation of COPD in India - A preliminary study. J Pulm Respir Med. 2015;5:238.

[15]. Narayanagowda DS, Golia S, Jaiswal J, Manasa SS. A bacteriological study of acute exacerbation of chronic obstructive pulmonary disease over a period of one year. Int J Res Med Sci. 2015;3:3141-6.

How to cite this article: G. Peter Praveen Herald, Suresh Kumar Cherlopalli. FACTORS DETERMINING OUTCOMES IN ACUTE EXACERBATIONS OF CHRONIC OBSTRUCTIVE PULMONARY DISEASE. Int J Intg Med Sci 2018;5(7):705-708. DOI: 10.16965/ijims.2018.127 